\title{
QUALITY INDICATORS- PERFORMANCE TOOLS OF BLOOD TRANSFUSION SERVICES
}

\author{
Lakshita Varshney1, Seema Gupta²
}

${ }_{1}^{1}$ Resident, Department of Immunohematology and Blood Transfusion, MGM Medical College and Hospital, Kamothe, Navi Mumbai. ${ }^{2}$ Associate Professor, Department of Immunohematology and Blood Transfusion, MGM Medical College and Hospital, Kamothe, Navi Mumbai.

\begin{tabular}{l}
\hline ABSTRACT \\
BACKGROUND \\
Blood transfusion services play a crucial role in patient's health care management. The quality of blood and blood products as well \\
as their injudicious use may affect the health care facility. Therefore, it becomes necessary for any blood centre to promote high \\
standards of quality in all aspects of its blood transfusion services. This can be achieved through implementation of quality \\
management systems, which can be monitored to provide high quality services. Quality management systems can be monitored \\
with the help of performance measures known as Quality Indicators (QI's). \\
Thus, our study is aimed to evaluate and analyse quality indicators as performance tools of our Blood Transfusion Services.
\end{tabular}

\section{MATERIALS AND METHODS}

This descriptive study was conducted in Department of Immunohematology and Blood Transfusion, MGM Medical College and Hospital, Kamothe, Navi Mumbai for a period of three years (2014 - 2016). The data was captured for eight most frequently used quality indicators in our blood bank, defined by NABH and was tabulated and charted.

\section{RESULTS}

On analysing the outcomes of the quality indicator parameters, we found that overall TTI\% was found to be $0.93 \%$ and ATRR was $0.16 \%$. Overall, wastage rate of whole blood and PRC were $2.05 \%$ and $3.19 \%$ respectively, while that of platelet it was $16.11 \%$ and for FFP and Cryoprecipitate it was 1.52\%. Overall, TAT for routine issues were 135.82 mins and for emergency issues it was 29.87 mins. The overall QC failure rate of PRBC, platelet, FFP and SwPC (Saline washed packed cells) was 10.67\%, 8.22\%, 8.63\% and $11.03 \%$ respectively. ADRR was found to be $1.15 \%$, while DDR was $8.23 \%$. The overall percentage of component issued were $98.18 \%$.

\section{CONCLUSION}

A well-structured blood transfusion service contributes towards a better healthcare in a hospital, which is reflected by quality indicators. Quality Indicator Data is acted upon by continuous measurement, identifying problems, root cause analysis, implementing corrective action, developing a quality improvement strategy (i.e. Preventive action), reporting and seeking opportunities for improvement. Quality indicators act like tools for continuous improvement to enable an organi sation to achieve its quality goals. Hence, by implementation of root cause analysis, corrective and preventive measures, the concerned authorities should ensure that the QI's are instituted in the right way for improving the quality of BTS in the organisation.

\section{KEYWORDS}

Quality Indicators, Blood Transfusion Service, Continuous Improvements.

HOW TO CITE THIS ARTICLE: Varshney L, Gupta S. Quality indicators- performance tools of blood transfusion services. J. Evolution Med. Dent. Sci. 2017;6(90):6348-6352, DOI: 10.14260/jemds/2017/1381

\section{BACKGROUND}

Now-a-days, blood transfusion services play a crucial role in patient's health care management. The services are primarily based on voluntary blood donation and appropriate utilisation of blood and blood products. The quality of blood and blood products as well as their injudicious use may affect the health care facility. Therefore, it becomes necessary for any blood centre to promote high standards of quality in all aspects of its blood transfusion services. This can be achieved through implementation of quality management systems, which can be monitored to provide high quality services.

'Financial or Other Competing Interest': None.

Submission 16-10-2017, Peer Review 08-11-2017,

Acceptance 14-11-2017, Published 20-11-2017.

Corresponding Author:

Dr. Lakshita Varshney,

C-2/119A,

Lawrence Road,

Keshav Puram, Delhi-110035.

E-mail: lakshita1989v@gmail.com

DOI: $10.14260 /$ jemds $/ 2017 / 1381$
Quality management systems can be monitored with the help of performance measures known as Quality Indicators (QI's).1,2,3 The American Association of Blood Banks (AABB) defines quality indicators as the specific performance measurements designed to monitor one or more processes during a defined time and are useful for evaluating service demands, production, adequacy of personnel, inventory control and process stability. ${ }^{4}$ Hence, these quality indicators become proof of the level of quality performances and the information gained through these can be used for continuous quality improvement. 5 The assessment of quality indicators can be done by using certain parameters where reestablished data and objectives can be used as benchmark. ${ }^{6}$

Thus, our study is aimed to evaluate and analyse quality indicators as performance tools of our Blood Transfusion Services.

\section{MATERIALS AND METHODS}

This descriptive study was conducted retrospectively in Department of Immunohematology and Blood Transfusion, MGM Medical College and Hospital, Kamothe, Navi Mumbai 
for a period of three years (2014 - 2016). The data was captured for eight most frequently used quality indicators in our blood bank, defined by National Accreditation Board for Hospitals and Healthcare Provider (NABH), ${ }^{7}$ namely-

1. Transfusion transmitted infection rate (TTI\%).

2. Adverse transfusion reaction rate (ATRR).

3. Wastage rate for each component.

4. Turnaround time for blood issues (TAT).

5. Component $\mathrm{QC}$ failure rate.

6. Adverse donor reaction rate (ADRR\%).

7. Donor deferral rate (DDR\%).

8. Percentage of components issued.

The formulae for calculations of quality indicators are described in Table 1 . The outcome of the quality indicators parameters were analysed and charted.

\begin{tabular}{|c|c|}
\hline TTI\% & $\begin{array}{c}\frac{\text { Combined TTI cases }}{(\mathrm{HIV}+\mathrm{HBV}+\mathrm{HCV}+\text { Syphilis }+\mathrm{MP})} \times 100 \\
\text { Total No. of Donors } \\
\end{array}$ \\
\hline $\begin{array}{c}\text { Adverse } \\
\text { Transfusion } \\
\text { Reaction Rate \% }\end{array}$ & $\begin{array}{l}\text { No. of adverse transfusion reactions } \times 100 \\
\text { Total no. of blood and components issued }\end{array}$ \\
\hline Wastage Rate \% & $\begin{array}{l}\text { No. of blood/ blood components } \\
\text { discarded x } 100 \\
\text { Total no. of blood/ blood components } \\
\text { issued }\end{array}$ \\
\hline $\begin{array}{c}\text { Turnaround } \\
\text { Time (TAT) } \\
\text { of Blood Issues } \\
\end{array}$ & $\begin{array}{c}\text { Sum of the time taken, } \\
\text { total number of blood and blood } \\
\text { components cross matched/reserved }\end{array}$ \\
\hline $\begin{array}{l}\text { Component QC } \\
\text { Failures (for each } \\
\text { component) }\end{array}$ & $\frac{\text { No. of components } \mathrm{QC} \text { failures } \mathrm{x} 100}{\text { Total no. of components tested }}$ \\
\hline $\begin{array}{l}\text { Adverse Donor } \\
\text { Reaction Rate \% }\end{array}$ & $\begin{array}{l}\frac{\text { No. of donors }}{\text { experiencing adverse reaction }} \times 100 . \\
\text { Total no. of donors }\end{array}$ \\
\hline $\begin{array}{l}\text { Donor Deferral } \\
\quad \text { Rate } \%\end{array}$ & $\begin{array}{c}\text { No. of donor deferrals x } 100 \\
\text { Total no. of donation + total no. of } \\
\text { deferrals }\end{array}$ \\
\hline $\begin{array}{c}\% \text { of Components } \\
\text { Issued }\end{array}$ & $\begin{array}{c}\text { Total component issues } \times 100 \\
\text { Total whole blood + component issues }\end{array}$ \\
\hline
\end{tabular}

\section{RESULT}

During the 3-year study period a total of 14,524 blood units were collected, of which 13,166 (90.65\%) were voluntary donations, whereas $1,358 \quad(9.35 \%)$ were replacement donations. The total number of components prepared during this period were 31,304 , which included packed red blood cells, random donor platelets, fresh frozen plasma and cryoprecipitates. The rest were either kept as whole blood or were discarded. The total whole blood and blood components issued were 22,244 .

On analysing the outcomes of the quality indicator parameters, we found that overall TTI\% was found to be $0.93 \%$ and ATRR was $0.16 \%$. Overall, wastage rate of whole blood and PRC were $2.05 \%$ and $3.19 \%$ respectively, while that of platelet it was $16.11 \%$ and for FFP and Cryoprecipitate it was $1.52 \%$. Overall, TAT for routine issues were 135.82 mins and for emergency issues it was 29.87 mins. The overall QC failure rate of PRBC, platelet, FFP and SwPC (Saline washed packed cells) was $10.67 \%, 8.22 \%, 8.63 \%$ and $11.03 \%$ respectively. ADRR was found to be $1.15 \%$, while DDR was
8.23\%. The overall percentage of component issued were $98.18 \%$.

The 3-year outcomes of quality indicator parameters are summarised in Table 2 and graphically represented as figures [Figure 1, Figure 2, Figure 3, Figure 4, Figure 5, Figure 6, Figure 7, Figure 8].

\begin{tabular}{|c|c|c|c|c|}
\hline QI's & 2014 & 2015 & 2016 & Overall \\
\hline TTI \% & 0.74 & 0.94 & 1.12 & 0.93 \\
\hline ATRR \% & 0.11 & 0.19 & 0.2 & 0.16 \\
\hline $\begin{array}{c}\text { Wastage Rate } \\
\% \\
\text { WB } \\
\text { PRBC } \\
\text { Platelet } \\
\text { FFP + Cryo } \\
\end{array}$ & $\begin{array}{c}1.69 \\
2.21 \\
16.65 \\
2.32\end{array}$ & $\begin{array}{l}2.48 \\
3.59 \\
15.6 \\
1.00\end{array}$ & $\begin{array}{c}1.98 \\
3.78 \\
16.08 \\
1.24\end{array}$ & $\begin{array}{c}2.05 \\
3.19 \\
16.11 \\
1.52\end{array}$ \\
\hline $\begin{array}{c}\text { TAT } \\
\text { Routine } \\
\text { Emergency }\end{array}$ & $\begin{array}{c}147 \\
\text { mins } \\
32.36 \\
\text { mins } \\
\end{array}$ & $\begin{array}{c}126 \\
\text { mins } \\
25.67 \\
\text { mins } \\
\end{array}$ & $\begin{array}{c}134.46 \\
\text { mins } \\
31.6 \\
\text { mins } \\
\end{array}$ & $\begin{array}{c}135.82 \\
\text { mins } \\
29.87 \\
\text { mins }\end{array}$ \\
\hline $\begin{array}{c}\text { QC Failure } \\
\text { Rate \% } \\
\text { WB } \\
\text { PRBC } \\
\text { Platelet } \\
\text { FFP } \\
\text { SwPC } \\
\end{array}$ & $\begin{array}{c}0 \\
7.1 \\
6 \\
8.33 \\
8.69\end{array}$ & $\begin{array}{c}0 \\
8.33 \\
14.58 \\
12.5 \\
4.16\end{array}$ & $\begin{array}{c}0 \\
16.6 \\
4.08 \\
5.06 \\
20.4\end{array}$ & $\begin{array}{c}0 \\
10.67 \\
8.22 \\
8.63 \\
11.03\end{array}$ \\
\hline ADRR \% & 0.94 & 1.24 & 1.29 & 1.15 \\
\hline DDR \% & 10.28 & 8.3 & 6.12 & 8.23 \\
\hline $\begin{array}{c}\% \% \\
\text { Components } \\
\text { Issue }\end{array}$ & 97.86 & 98.99 & 97.71 & 98.18 \\
\hline
\end{tabular}

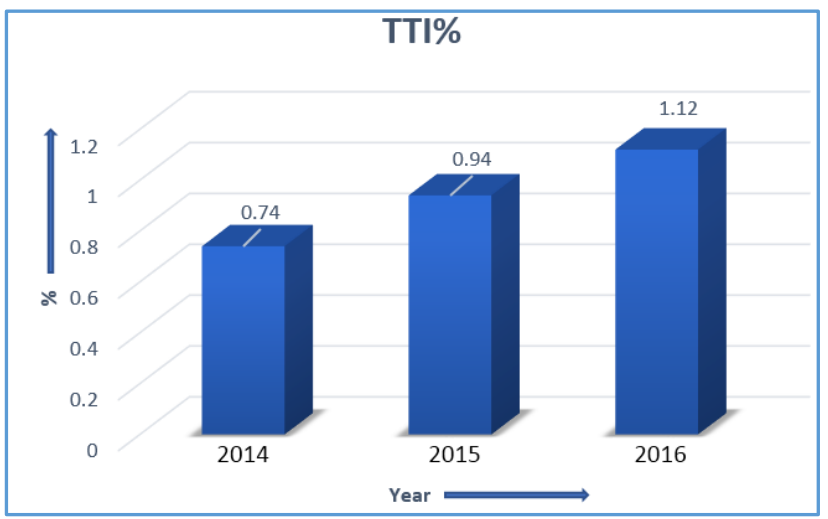

Figure 1. Transfusion Transmitted Infection Rate

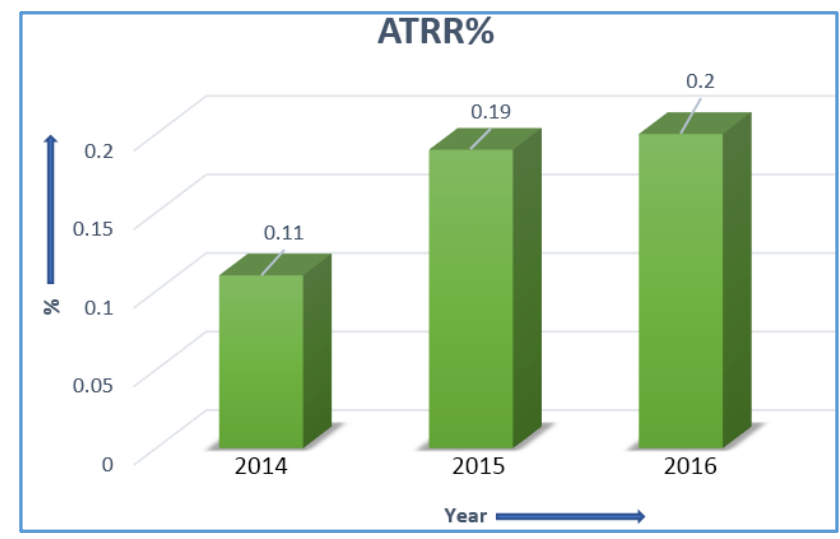

Figure 2. Adverse Transfusion Reaction Rate 


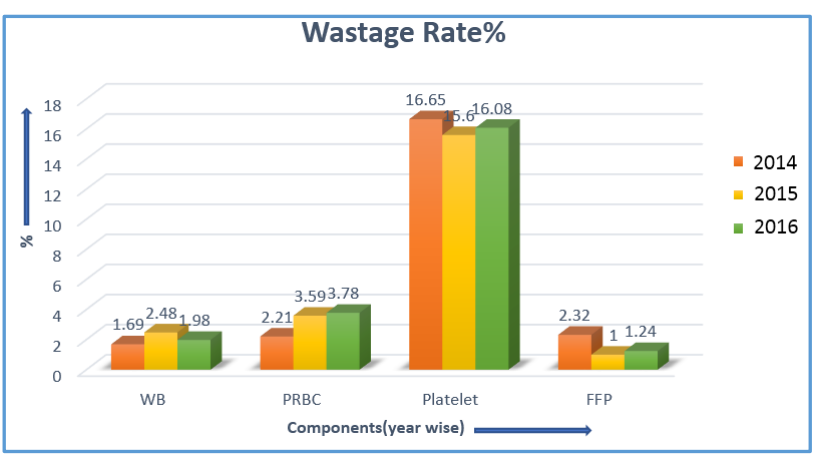

Figure 3. Wastage Rate of Blood and Blood Components

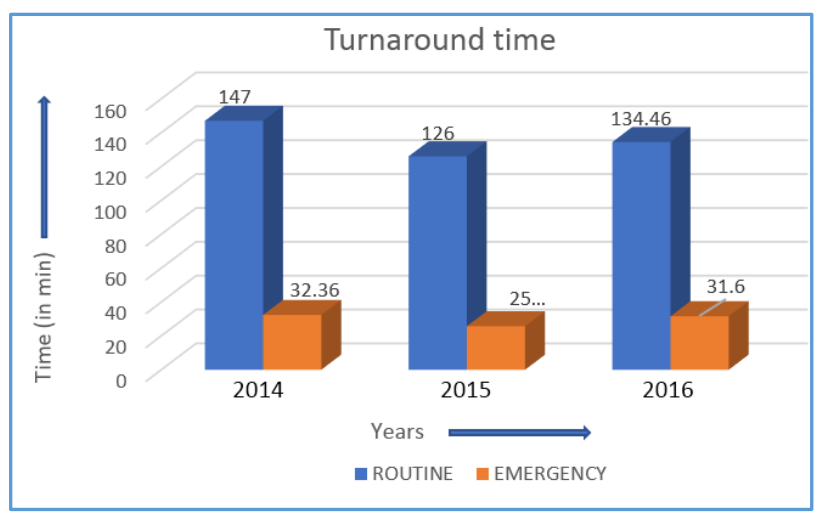

Figure 4. Turnaround Time of Routine and Emergency Issues

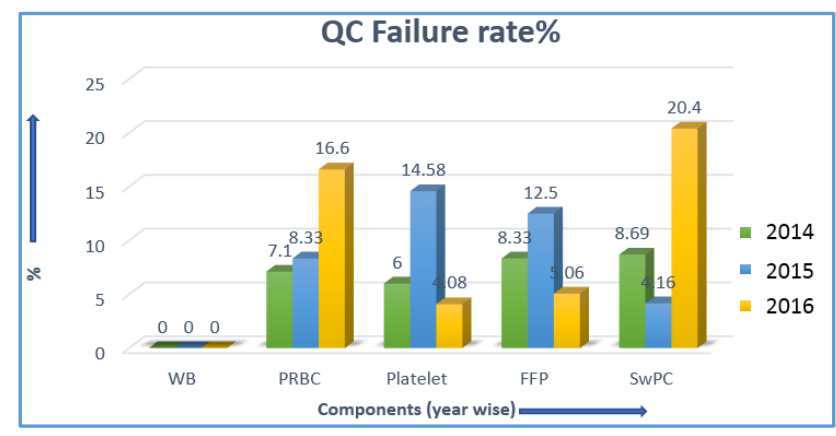

Figure 5. QC Failure Rate of Blood Components Prepared

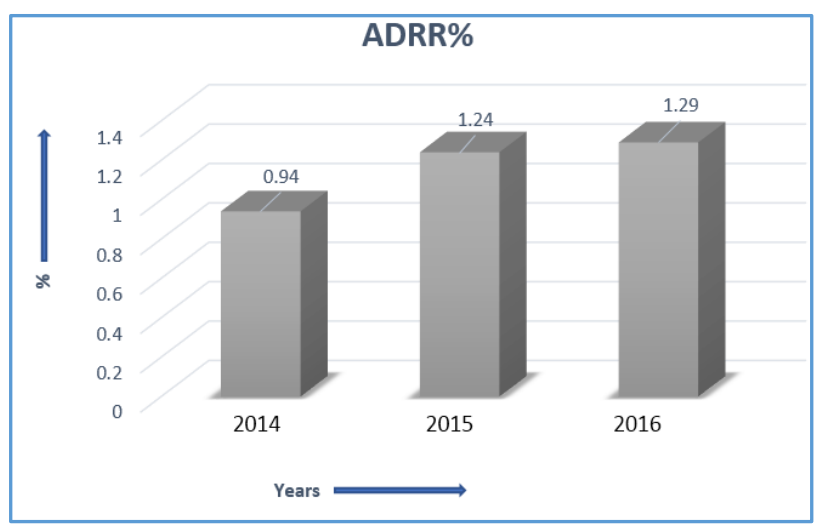

Figure 6. Adverse Donor Reaction Rate

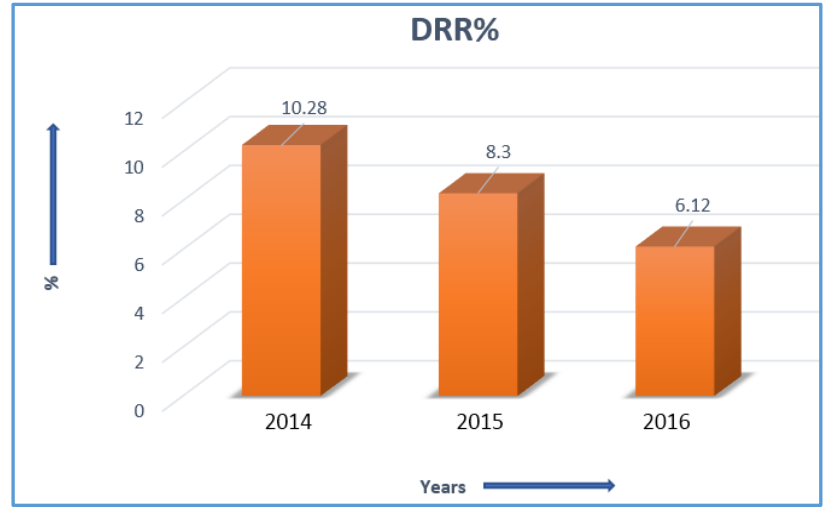

Figure 7. Donor Deferral Rate

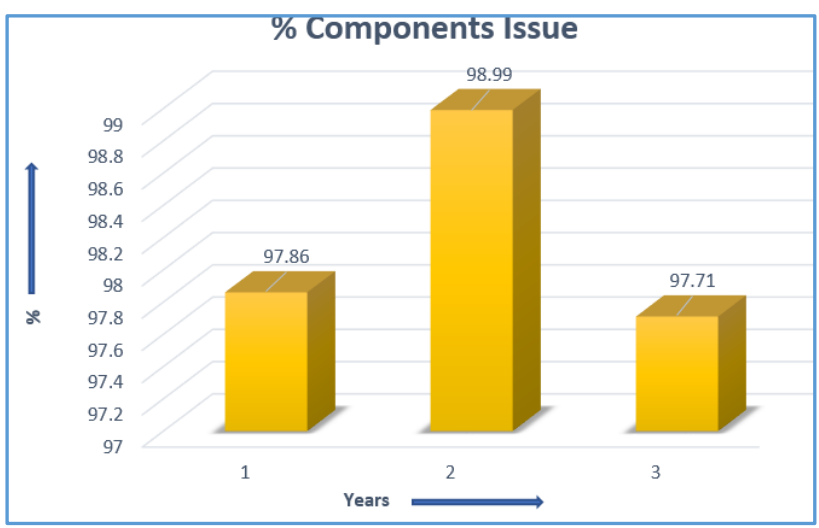

Figure 8. Percentage of Component Issued

\section{DISCUSSION}

A well-structured blood transfusion service contributes towards a better healthcare in a hospital, which is reflected by quality indicators. ${ }^{8}$ Blood components are frequently ordered and utilised in many hospitals without proper analysis of the real needs, thus wasting a very important resource. Many policies have been developed to reduce this inappropriate use of blood and blood components such as guidelines regarding blood transfusion practice, education of the clinicians and self-audits by the blood banks. ${ }^{3}$ Quality indicators are one of the tools for evaluating and monitoring blood transfusion practice. Quality Indicator Data is acted upon by 4 continuous measurement, identifying problems, root cause analysis, implementing corrective action, developing a quality improvement strategy (i.e. Preventive action), reporting and seeking opportunities for improvement. $^{9}$

In our study, we found that overall TTI $\%$ was $0.93 \%$. The rate was seen progressively increasing from $0.74 \%$ in 2014 to $1.12 \%$ in 2016 . This may be because number of donations per year also increased since 2014. Higher prevalence was found in replacement donors. Among the five transfusion transmitted infections tested in our blood bank, HBsAg was found to be more seroprevalent followed by HIV. Similar finding was reported in the study done by Fernandes et al (2010), ${ }^{10}$ who found TTI prevalence to be $0.6 \%$. Another study by Zulfikar et al (2102) ${ }^{11}$ also showed similar trend of prevalence to be $0.82 \%$. Higher transfusion transmitted infections rate is one of the major threat towards blood safety. Therefore, proper donor screening, reliable screening 
tests and counselling of TTI positive donors can effectively help in prevention of such transmission. ${ }^{12}$

Another major patient related parameter, i.e. Adverse transfusion reaction rate found in our study was $0.16 \%$ overall. This showed an increased trend from $0.11 \%$ in 2014 to nearly constant rate of $0.19 \%$ and $0.20 \%$ in 2015 and 2016 respectively. Majority of the cases were caused by allergic reactions and FNHTR's (90\%). In the year 2015 - 2016, the rate did not vary much as we undertook various lectures and education programs for the clinicians and nurses within the hospital regarding the blood transfusion practices and guidelines. Our blood bank is also now enrolled with National Haemovigilance Program of India adding further to surveillance program. Similar findings were reported by Bhattacharya et al (2011), ${ }^{13}$ which showed rate to be $0.18 \%$. Chakravarty-Vartak et al (2016) ${ }^{14}$ had an incidence of $0.16 \%$, which is comparable to our study. Use of newer technologies like leukoreduction, reporting of all adverse events and continuous education to medical and paramedical staff will help in reducing the ATR's ${ }^{15}$ in any blood centre.

The wastage rate overall in our setup was $2.05 \%$ for whole blood, $3.19 \%$ for packed red blood cells, $16.11 \%$ for platelets and $1.52 \%$ for fresh frozen plasma and cryoprecipitates. The most common discarded units were platelets due to date of expiry followed by seroreactivity. This contrasts with various other studies like Suresh et al (2015) ${ }^{16}$ and Kaur et al (2016),17 where the most common cause of wastage of blood units was TTI positivity, though the most common units discarded remained platelets among the blood components. Other causes for wastage of blood units include breakage or leakage while processing of blood, contamination and haemolysis. Blood being a most vital resource of treatment modalities should be used in most appropriate manner. Judicious use of blood can minimise the number of discarded blood to a reasonable rate. ${ }^{1}$ Like mentioned previously, proper donor screening and counselling will effectively reduce the collection of such positive units. Regular audits and analysis for wastage of blood and blood components along with following of FIFO (First In First Out) policy may help in further reduction of wastage rate. ${ }^{6}$

Turnaround time (TAT) may be explained as sum of time taken from receipt of blood requisition, reservation till issue of blood and blood components. Overall, TAT for routine cases found in our study was 135.82 mins. Although, we came across with a similar study by Gupta et al (2015) ${ }^{18}$ as 153 mins. However, overall TAT for emergency cases was 29.87 mins comparable to the study done by Ramanathan et al (2015) ${ }^{19}$ reporting 30.3 mins. We found more turnaround time in 2014, therefore training of the technical staff to act momentarily for blood requests eventually led to reduced turnaround time in 2015 and 2016. As such, no specific recommendations for turnaround time have been established and very few studies are available to compare.

Overall, QC failure rate found in our study was $10.67 \%$ for packed red blood cells, $8.22 \%$ for platelets, $8.63 \%$ for fresh frozen plasma and $11.30 \%$ for saline washed packed cells. According to the National Accreditation Board for Hospitals and Healthcare Provider (NABH) Quality standards and Drug and Cosmetic Act, 1940 and its rules 1945, 1\% of component is tested for Quality Control out of which $75 \%$ should match the acceptable ranges.7,20 In our study, we found that in all three years the $Q C$ failure rate was variable but still all the components were meeting the quality requirement. No failure rate was observed for whole blood, as whole blood was not much kept in stock. Upgradation and training of technical staff for component separation techniques will help in further reducing $\mathrm{QC}$ failure rate.

On analysing adverse donor reaction rate, it was found that the overall rate was $1.15 \%$. The rate was almost similar in three years of study with slightly higher rate in 2016. Related results were reported by Abhishekh et al (2013) ${ }^{21}$ and Kumar et al (2014) $)^{22}$ showing $2.03 \%$ and $0.93 \%$ respectively. This variation can be attributed to donor demographics or pre-donation and post-donation counselling methodologies. Majority of the reactions were vasovagal in nature, comprising of $90 \%$ of all reactions. Female donors were observed with higher rate of adverse donor reaction. The following measures can be taken to minimise the donor reaction, which includes longer waiting period in airconditioned rooms with appropriate fluid intake before and after the donation, donation under supervision with adoption of good motivational strategies and counselling methods. ${ }^{23}$

With context to donor deferral rate, overall it was found to be $9.3 \%$. The most common cause for deferral found in our study was low haemoglobin followed by medication history. Other causes include history of malaria, dengue or typhoid, dental procedures and vaccination. A study by John et al (2015) ${ }^{24}$ reported $5.12 \%$ as their deferral rate. Another study by Rehman et al (2012) ${ }^{25}$ reported $12.4 \%$ as their donor deferral rate. Likewise, Agnihotri et al (2010) ${ }^{26}$ reported their donor deferral rate to be $11.6 \%$. This wavering seen in the donor deferral rates can be due to varying demographics of study population. Modification of donor recruitment strategies, rationalisation of deferral criteria and counselling of deferred donors ${ }^{25}$ can be applied for reducing the donor deferral rate.

We found that the overall percent component issue in our blood bank was $98.18 \%$. It was more in the year 2015 (98.99\%) than $2014(97.86 \%)$ and 2016 (97.71\%). We are not into $100 \%$ components, as during big camps all collected blood is not separated into components due to shortage of staff. Therefore, few units are kept as whole blood in stock.

\section{CONCLUSION}

Despite of numerous improvements in the field of transfusion medicine, national guidelines regarding the benchmarks for quality indicators parameters are still lacking. Most of the benchmarks defined are either based upon the analysis of data published by assorted studies or the blood banks have defined their individual benchmarks by analysing their own previous year statistics making it one of the major limitation. However, for better transfusion service, quality goals should be achieved with continuous improvements. ${ }^{27}$ Quality indicators acts like tools for continuous improvement to enable an organisation to achieve its quality goals. Hence, by implementation of root cause analysis, corrective and preventive measures, the concerned authorities should ensure that the QI's are instituted in the right way for improving the quality of BTS in the organisation.28

\section{REFERENCES}

[1] Morish M, Ayob Y, Naim N, et al. Quality indicators for discarding blood in the National Blood Center, Kuala Lumpur. Asian J Transfus Sci 2012;6(1):19-23. 
[2] Bhatnagar NM, Soni S, Gajjar M, et al. Performance indicators: a tool for continuous quality improvement. Asian J Transfus Sci 2016;10(1):42-7.

[3] Devi KM, Sharma AB, Singh LD, et al. Quality indicators of blood utilization in the tertiary care center in the north-eastern India. J Dent Med Sci 2014;13:50-2.

[4] Roback JD, Grossman BJ, Harris T, et al. Technical Manual. 17th edn. Bethesda, Maryland: American Association of Blood Banks 2011: p. 24.

[5] Anyaegbu CC. Quality indicators in transfusion medicine: the building blocks. ISBT Sci Ser 2011;6:3545.

[6] Strengthening quality management systems in blood banks, Technical manual, NBTC, NACO. Ministry of Health and Family Welfare, Govt. of India 2016.

[7] National Accreditation Board for Hospitals and Healthcare Providers (NABH), Quality Standards, 3rd ed. 2016.

[8] Roy AD, Pal A. Evaluation of 'Wastage Rate' of blood and components - an important quality indicator in blood banks. Article no. BJMMR 2015.458. BJMMR 2015;8(4):348-52.

[9] Shadler A. MT (ASCP)SBB. Quality Management in the Laboratory. College of American Pathologists. Quality Management in Clinical Laboratories. UCLA Quality Indicators. 2010.

[10] Fernandes H, D'souza PF, D'souza PM. Prevalence of transfusion transmitted infections in voluntary and replacement donors. Indian J Hematol Blood Transfus 2010;26(3):89-91.

[11] Zulfikar A, Umaru M, Shreesha K. Seroprevalence of transfusion transmitted infections among blood donors in Mangalore. Medical Innovatica 2012;1(2): 24-7.

[12] Leena MS, Mohd Shafee. Trend and prevalence of transfusion transmitted infections among blood donors in rural teaching institute, south India. Journal of Pathology of Nepal 2012;2(3):203-6.

[13] Bhattacharya P, Marwaha N, Dhawan HK, et al. Transfusion-related adverse events at the tertiary care centre in North India: an institutional hemovigilance effort. Asian J Transfus Sci 2011;5(2):164-70.

[14] Chakravarty-Vartak U, Shewale R, Vartak S, et al. Adverse reactions of blood transfusion: a study in a tertiary care hospital. Int J Sci Stud 2016;4(2):90-4.

[15] Kumar P, Thapliyal R, Coshic P, et al. Retrospective evaluation of adverse transfusion reactions following blood product transfusion from a tertiary care hospital: a preliminary step towards hemovigilance. Asian Journal of Transfusion Science 2013;7(2):10915.
[16] Suresh B, Babu SKV, Arun R, et al. Reasons for discarding whole blood and its components in a tertiary care teaching hospital blood bank in South India. J Clin Sci Res 2015;4:213-9.

[17] Puneet K, Rupinder K, Victor M, et al. Incidence and causes of wastage of blood \& blood components in a blood bank of tertiary care hospital: a retrospective study. Journal of Dental and Medical Sciences 2016;15(9):Ver. IV. 108-10.

[18] Gupta A, Gupta C. Role of National Accreditation Board of Hospitals and Healthcare Providers (NABH) core indicators monitoring in quality and safety of blood transfusion. Asian J Transfus Sci 2016;10(1):37-41.

[19] Ramanathan T, Usha KC. Turn around time (TAT) for emergency blood issue: a quality indicator. 39th ISBTI Annual Conference, TRANSCON 2014, Patiala. Asian J Transfus Sci 2015; 9:1144.

[20] The Drugs and Cosmetics Act and Rules. The Drugs and Cosmetics Act, 1940 (23 OF 1940) (As Amended Up To The 30th June, 2005) And The Drugs And Cosmetics Rules, 1945 (As Amended Up to The 30th June, 2005). Ministry of Health and Family Welfare, Government of India.

[21] Abhishekh B, Mayadevi S, Usha KC. Adverse reactions to blood donation. Innovative Journal of Medical and Health Science 2013;3(4):158-60.

[22] Kumar KM, Soni R, Sravan C, et al. Adverse reactions of blood donation: a prospective observational study. Journal of Evolution of Medical and Dental Sciences 2014;3(13):3367-77.

[23] Agnihotri N, Marwaha N, Sharma RR. Analysis of adverse events and predisposing factors in voluntary and replacement whole blood donors: a study from north India. Asian Journal of Transfusion Science 2012;6(2):155-60.

[24] John F, Varkey MR. Evaluation of blood donor deferral causes in a tertiary hospital, South India. International Journal of Biomedical and Advance Research 2015;6(3):253-8.

[25] Rehman S, Arif SH, Mehdi G, et al. The evaluation of blood donor deferral causes: a tertiary care centrebased study. J Blood Disorders Transf 2012;3(5):131.

[26] Agnihotri N. Whole blood donor deferral analysis at a center in Western India. Asian Journal of Transfusion Science 2010;4(2):116-22.

[27] Vuk T. Role and importance of QI's in QM and HV: From monitoring to improvement and saving. Croatian Inst of Transfusion Medicine, Zogreb, Crotia. www.ihnorg.com/wp.../08/2-Vuk-T-IHS-Brussels

[28] 3.6 Quality indicators for blood transfusion. Submitted by obuadmin on Wed, 02/13/2013 - 00:57. Optimal Blood Use. EU. 